\title{
A FORMAÇÃO DE PROFESSORES PARA A EDUCAÇÃO BÁSICA
}

BASTOS, Manoel de Jesus ${ }^{1}$

BASTOS, Manoel de Jesus. A Formação de Professores para a Educação Básica. Revista Científica Multidisciplinar Núcleo do Conhecimento. Ano 02, Ed. 01, Vol. 14, pp. 82-97 Janeiro de 2017 ISSN: 2448-0959

\section{RESUMO}

O presente trabalho aborda questões relacionadas ao perfil dos professores da educação básica, mais precisamente, dos anos iniciais do Ensino Fundamental e apresenta, explicitamente, a acentuada divergência existente entre a teoria, apresentada e exigida pela LDB - Lei de Diretrizes e Bases, e a prática pedagógica exercida hodiernamente em nosso país e tendo em vista a atuação inadequada de professores generalistas e os de nível superior. Admite-se que ainda há a errônea prática de direcionamento de professores de nível médio, e às vezes leigos, para ministrarem aulas na educação infantil, considerada área de maior complexidade. Objetiva-se esclarecer que a base é que precisa de profissionais com formação específica para poder, efetivamente, desenvolver continuamente, o processo ensinoaprendizagem, evitando riscos de desmoronamentos ao longo dos estudos. Professores devem estar preparados não somente para atender a demanda dos educandos, mas para oferecer um produto qualitativo, atendendo as normas educacionais e superando as expectativas que a sociedade espera.

Palavras-Chave: Professores, Educação, Formação, Sistema, Pedagógica.

\footnotetext{
${ }^{1}$ Formado em Normal Superior pela UESPI (Universidade Estadual do Piauí), Pósgraduado em Supervisão Escolar pela Faculdade de Teologia Hokemãh - Fateh e Mestrando em Educação pela Anne Sullivan University.
} 


\section{INTRODUÇÃO}

Nos últimos vinte anos vêm se desenvolvendo um amplo debate a respeito da formação de professores para a educação básica em nosso país, com convergências e discrepâncias, ao mesmo tempo, essa questão parece ainda estar distante do que se almeja, ao longo de décadas. Dentre outras circunstâncias empecilhadoras, acredita- se na falta de interesse à docência, notadamente, pela baixa remuneração na área e a inadequação de políticas e propostas pedagógicas que venham dar suporte de agregação ao setor, permitindo um efetivo enfrentamento aos desafios constantes e a implementação de diretrizes curriculares, na direção de um projeto integrado às necessidades da sociedade.

Partindo dessa premissa, observa-se que a busca de uma perspectiva de análise dos problemas reais tende a ser mais radicais, delineando suas causas principais e estruturais, como ponto de partida para a sinalização das soluções. E acreditando-se que nunca é tarde demais para uma prévia reflexão e busca de ações norteadoras aos problemas que vem afetando o sistema educacional brasileiro, acende-se a perspectiva de que é hora, de cada um apostar na revolução educacional positiva, fazendo eticamente a sua parte.

Em resumo: O processo pedagógico em curso não é universal, sendo mais ligeiramente desenvolvido nos países onde a educação é considerada prioridade e os investimentos para a área não são poupados.

A maioria dos professores da educação básica no Brasil, mais de $57 \%$ não possuem licenciatura na disciplina que trabalham e pouco mais de $22 \%$ dos que estão em salas de aulas, não têm qualquer licenciatura, sendo a Região Nordeste a que concentra maior número de professores sem licenciatura em áreas específicas disciplinares e $66 \%$ não são formados na área em que trabalham. Todavia, a intensidade de preocupação com a falta de formação específica desses profissionais é, ainda, bastante volumosa, tendo em vista que o primeiro pontapé rumo ao desenvolvimento de um Estado inicia-se a partir de uma boa preparação dos protagonistas da educação: os professores. 
É preciso criar-se certos mecanismos que possam devolver a credibilidade docente e a valorização desses profissionais deve ser priorizada como a profissão da excelência, pelo contrário o desprazer e o dissabor na caminhada, continuarão amargos e os resultados insatisfatórios.

\section{PROFESSORES LEIGOS NO BRASIL}

Há algumas décadas a atuação de professores leigos na área educacional era bastante comum. Ora pela carência regional, ora pela negligência do sistema educacional brasileiro, essa prática corria a solto, principalmente nas regiões mais carentes do nosso país, sendo melhorada mias tarde com a oferta de cursos de aprimoramento e habilitação para esses profissionais. Mesmo assim, não é difícil, em pleno século XXI, deparar-se com pessoas sem a devida habilitação, atuando na área pedagógica, ferindo assim, o artigo 62 da Lei de Diretrizes e Bases da Educação Nacional, quando afirma que "a formação de docentes para atuar na educação básica far-se-á em nível superior, em curso de licenciatura, de graduação plena, em universidades e institutos superiores de educação, admitida, como formação mínima para o exercício do magistério na educação infantil e nos cinco primeiros anos do ensino fundamental, a oferecida em nível médio na modalidade normal”.

Por que será que isso acontece somente na área da educação? Sabe-se que o advogado não tem permissão para resolver uma causa se não estiver de posse do registro da $O A B$, o médico não pode receitar um paciente se não portar do registro no CRM, o enfermeiro se não tiver o COREN, e por que uma pessoa pode atuar na área pedagógica, se não é titular do magistério?

Se bem que a nova legislação educacional tem oferecido, nos últimos anos, algumas reformas relevantes nos sistemas educacionais estaduais e municipais com perspectivas positivas e extremamente aceitáveis na qualificação da carreira dos professores, abrindo, de certa forma, os leques do desenvolvimento e crescimento educacional brasileiro. Não se pode, em hipótese nenhuma, começar a pensar no desenvolvimento da criança, do adolescente e do jovem, se previamente, não houver investidura qualificativa nos professores. A partir de então ficaria mais fácil pensar 
nessas pessoas com suas diversidades culturais e valores dentro da sociedade, seja na família, na escola, no trabalho etc.

Infelizmente, ainda há certa resistência de muitos professores graduados e até mesmo especialistas que menosprezam o ensino infantil, alegando a complexidade da tarefa e optando pelo ensino das séries finais do ensino fundamental e ensino médio, esquivando-se de um dever exclusivamente seu. Por isso, quase sempre, a educação infantil e séries iniciais são ainda trabalhadas por profissionais que não dispõe dos requisitos previstos na Lei de Diretrizes e Bases - LDB e desprovidos de conhecimentos científicos e psicológicos, mergulham no faz de conta de ensinar.

E por considerar que a base da educação é que realmente necessita de um preparo consolidado para o desenvolvimento humano, faz-se necessário a criação de pressupostos básicos com a elaboração de propostas pedagógicas que visem o norteamento dessa faixa etária com o delineamento da formação prévia dos professores que trabalham nas séries iniciais do ensino fundamental. (CAMPOS, 1994)

Em se tratando de professores leigos, outro aspecto que não se pode deixar de abordar é o empecilho "acomodação" enraizada naqueles que isentos de compromissos com a educação, deixam de aprimorarem-se achando que não compensa, pelo fato da baixa remuneração na área da docência. Ora, o artigo 61 da Lei de Diretrizes e Bases - LDB prescreve que são considerados profissionais da educação escolar básica aqueles que estando em efetivo exercício na área, tenham sido formados em cursos reconhecidos pelo MEC em nível médio ou superior para a docência na educação básica. No entanto, há, ainda, aqueles que se atrelando ao "jeitinho brasileiro", atropelam a lei, ministrando aulas, em cursos diversos, sem ter, no mínimo, o perfil exigido pela LDB. Outros, tendo formações específicas, trabalham em áreas distintas que certamente não seria o seu forte para a consumação dos objetivos norteadores previstos na legislação.

Sendo o ensino infantil e os anos iniciais do ensino fundamental o alicerce da construção educacional, o pilar ferrenho para consolidação da cidadania, porque 
faltam ênfases e cuidados específicos nesta área? Por que os profissionais a subestimam, argumentando dificuldades em exercê-la? Ora, assim como uma casa para poder resistir os fenômenos naturais, precisa dos melhores profissionais para uma edificação sólida e compacta evitando sobremaneira, os desmoronamentos com as primeiras chuvas, da mesma forma as nossas crianças carecem de profissionais qualificados na área educacional, com embasamentos, compromissos e responsabilidades no processo formativo, oferecendo todas as garantias da continuidade de uma educação segura e sem tropeços.

Há, portanto, a necessidade de uma revisão da compreensão da prática pedagógica do professor nas séries iniciais do ensino fundamental, visando à garantia da legitimidade, uma vez que ele é considerado e muito bem visto pela sociedade como articulador de saberes profissionais, construindo e reconstruindo seus conhecimentos na medida em que vai precisando. (Tardif, 2000)

Todavia, é preciso delinear a formação do professor à sua prática pedagógica quotidiana, levando-se em conta os desvios funcionais existentes na rede pública de ensino, ou seja, professores com formação em a área específica pode não ser bem sucedido em áreas diferentes.

A formação do professor deve estar relacionada à sua área para que ele possa desenvolver, de forma eficiente, as suas tarefas disciplinares no âmbito pedagógico. É absolutamente correto afirmar que para o profissional obter resultados positivamente almejados, faz-se necessário trabalhar com amor e dedicação. "Se realmente gosta de sua profissão, obviamente fará um excelente trabalho e colherá bons resultados", pelo contrário, eles aparecerão por consequências.

E nesta perspectiva de análise da formação dos professores e seus respectivos valores, é que os estudos a respeito dos seus saberes ganham ênfase e dão um salto na busca das identificações dos conhecimentos empíricos na prática docente, cuja concepção defende a investidura dos saberes de que o professor é o seu principal condutor. A sua formação propiciará maiores rendimentos e, consequentemente, melhores resultados no seio do sistema educacional. 
$\mathrm{Na}$ década de 90 , buscaram-se novos paradigmas com o intuito de entender, com explicidade, a prática pedagógica, corrigindo-a e resgatando o verdadeiro papel do professor, dando ênfase ao desenvolvimento pessoal e profissional docente. Isso porque a profissão docente encontrava-se reduzida a um conjunto de competências técnicas gerando elevadas discrepâncias entre o eu pessoal e o eu profissional. A partir daí os estudos sobre os saberes docentes ganharam impulsos e começaram a aparecer na literatura, cujo objetivo era a identificação dos conhecimentos implícitos na prática docente, e o professor passaria a ser o verdadeiro protagonista em estudos e debates, mergulhando de cabeça no universo pedagógico. (Nóvoa-1995) Então houve, notadamente, uma acentuada mudança nos estudos que passaram a ter reconhecimento e consideração nos saberes construídos pelos professores, que até então não eram reconhecidos.

Todavia, procura-se ainda, resgatar a importância de se considerar o professor na sua específica formação e/ou auto formação, na reelaboração dos saberes inicial em confrontação à sua prática realizada. Deste modo, seus conhecimentos constituemse a partir de uma ação-reflexão-ação sobre a prática pedagógica. A reflexão tem sido uma tendência indispensável à prática docente, levando-se em conta os diversos equívocos cometidos no decorrer das atividades pedagógicas. Acredita-se que somente através dela poderia detectar-se àquilo que não se produziu, eficazmente, e traçar obviamente novos objetivos na busca de melhores resultados.

\section{A FORMAÇÃO DOS PROFESSORES NO BRASIL}

A formação inicial e continuada do professor faz-se necessário, uma vez que ele é considerado o sujeito de um saber e de um fazer, colocando suas próprias ações e pensamentos à disposição da docência em busca de novas luzes para caminhos obscuros e mascarados da sociedade.

Os saberes escolares e docentes subentendidos e as crenças epistemológicas não seriam valorizados tampouco investigados pela pesquisa acadêmica, como pelos programas de formação de professores. Período esse, em que as práticas docentes 
tenham tido início investigativo, as pesquisas não tinham o objetivo de valorizá-los como formas válidas do saber. (Linhares-1996)

Em se tratando da formação de professores, esses revelam a existência de um conhecimento pedagógico que não se adquire ou se constrói de imediato, mas que vai sendo construído ao longo da carreira, ou seja, à medida que se impregna os métodos docentes.

A Lei de Diretrizes e Bases da Educação Nacional assegura em seu artigo 61, I, II e III que todos os docentes da educação básica possuam formação específica em nível superior. Todavia, os dribles do sistema mascaram tal artigo, desconsiderando e atropelando a lei e, talvez usando do comodismo profissional, deixam de buscar aquilo que é óbvio para si mesmo e para a educação: a formação específica. Há registros de que em 2013 , apenas $74,8 \%$ dos professores tinham formação superior, ou seja, $1 / 4$ desses profissionais ministravam aulas sem ter a formação devida. (Inep)

Contudo, nos últimos anos, a conscientização da necessidade de uma formação adequada às exigências do mercado de trabalho, os incentivos oferecidos pelos Planos de Careira do Magistério, a criação do Piso Salarial Nacional do Magistério, além de outros, deu uma guinada observável nas mudanças de níveis de formação. Antes era muito mais difícil cursar uma faculdade. Hoje, há certa facilidade. Se o professor tiver dificuldades de ir á uma universidade, ela virá até ele.

Atualmente, à proporção em que se enfrentam os problemas existentes na educação, avoluma-se a preocupação com a falta das licenciaturas, tanto no que diz respeito às estruturas institucionais que as oferecem, quanto aos currículos ou conteúdos formativos. Se bem que são muitos os fatores que propiciam uma boa ou má formação: as políticas educacionais, o investimento da educação básica, os aspectos culturais, sejam nacional, regionais ou locais, as estruturas das escolas, a formação dos gestores e, principalmente as condições sociais e de escolarização dos pais de alunos, mas precisamente, das camadas sociais menos favorecidas ou isentas da conscientização, de que somente a educação é a principal responsável pela mudança social ascendente do indivíduo. 


\section{POLÍTICAS EDUCACIONAIS}

Ao longo dos anos em nosso país, a política educacional tem sido definida de formas diferenciadas, levando-se em conta o envolvimento do Estado com políticos diversos, quando deveria ser manejada pela sociedade, uma vez que o povo emana do poder, respeitando os seus direitos e garantindo o bem comum. Imagina-se que a construção e uma política pública não deve ser fácil, tendo em vista englobar uma nação, seus interesses, perspectivas e valores. E esses itens não devem ser menosprezados por aqueles que moldam a educação de um povo, mas há em meio toda essa normatização, ações que fruíram como marco na definição de metas educacionais que realmente necessitam ser efetivadas: a implementação da Lei de Diretrizes e Bases da Educação Nacional - LDB, a Lei do Piso Salarial Nacional do Magistério, o Fundo de Manutenção e Desenvolvimento da Educação Básica e Valorização dos Profissionais da Educação - FUNDEB, Lei 11.738/2008 que determina aos entes federados, a criação ou reformulação dos Planos de Carreira e Remuneração do Magistério, além de outros.

\section{INVESTIMENTOS DA EDUCAÇÃO BÁSICA}

O Brasil é o país que dá mais do PIB (Produto Interno Bruto) para a educação. Porém o gasto por aluno é pouco, isso porque o número de alunos é muito alto e quando o investimento é dividido, fica diluído. No entanto, o investimento do Brasil por aluno é um dos mais baixos do mundo. A educação de um brasileiro é feita com $1 / 3$ do valor gasto com um estudante dos países ricos, em média. De acordo o PNE (Plano Nacional de Educação), o investimento da educação pública será ampliado, de forma a atingir, no mínimo, 7\% (sete por cento) do Produto Interno Bruto do país no quinto ano de vigência e, no mínimo, o equivalente a 10\% (dez por cento) no final do decênio. (Meta $20 \mathrm{PNE}$ )

\section{ESTRUTURA DAS ESCOLAS BRASILEIRAS}

É extremamente correto afirmar que o espaço físico das escolas brasileiras precisam oferecer conforto e comodidade aos nossos alunos. Mas, nem sempre esses padrões 
de exigências são atendidos, considerando que atualmente menos de $1 \%$ (um por cento) das escolas brasileiras tem a infraestrutura ideal, ou seja, apenas $0,6 \%$ (zero vírgula seis por cento) delas possuem adequação próxima da ideal. Essa falta de estruturação, principalmente na zona rural, implica numa educação retrógrada, lerda e, é claro, sem avanços significativos exigidos ou previstos pelo sistema. (UNB Universidade de Brasília)

\section{FORMAÇÃO INICIAL DOS PROFESSORES}

As instituições de ensino superior, seja no sistema presencial ou à distância (EAD), uma vez credenciadas pelo Ministério da Educação e Cultura, responsabilizam-se pela condução do ensino superior, com o intuito de viabilizar a melhoria na qualidade da formação desses docentes, imprescindíveis à tão árdua tarefa equilibradora da sociedade. Por saber que o papel das instituições de ensino e o dos professores é ensinar educando, garantindo e propiciando, de certa forma, um futuro norteador e sadio, preocupa-se, por entender que nos seus conhecimentos básicos, para interpretar um mundo complexo, certamente não haverá a verdadeira condição de formação de valores e, principalmente, para o exercício da cidadania.

A profissionalização é uma gama de características da profissão docente que exige conhecimentos e habilidades necessárias ao exercício profissional e implica na obtenção de um espaço autônomo, específico à sua função com valores imensuráveis reconhecidos pela sociedade. Não pode haver autenticidade de uma profissionalização sem a construção de uma base formativa sólida de conhecimentos e meios de ação. De modo que há uma solicitação gritante para a saída do improviso, do professor quebra-galho para o adentra mento na concepção de um profissional com condições de enfrentamento aos mais complexos problemas existentes na sociedade, construindo soluções através de suas ações provindas dos seus recursos cognitivos e afetivos. (RAMALHO, NUÑEZ e GAUTHIER - 2003)

A formação inicial é extremamente necessária, no currículo docente, uma vez que faz parte das exigências da LDB - Lei de Diretrizes e Bases e ao mesmo tempo, vem favorecer uma gama de possibilidades na melhoria e aplicabilidade de um ensino de 
qualidade. Os conhecimentos de um profissional não podem ficar limitados simplesmente a uma formação. Mesmo sabendo que o conhecimento profissional vai sendo construído ao longo da carreira, apesar de trajetórias distintas, a necessidade de busca do aprimoramento é imprescindível.

Todavia, discute-se também o lócus da formação, assunto que tem envolvido a formação inicial dos professores das séries iniciais do ensino fundamental, e que tende a deixar de ser realizada nos cursos normais para serem realizados nas Universidades e Institutos de Ensino Superiores de Educação. Esse projeto tem sido objeto de discussões desde a apresentação de sua proposta na LDB 9394/96.

De forma, que há uma necessidade muito grande e urgente de encontrar-se a melhor forma de capacitar professores para poderem, efetivamente, realizarem o enfrentamento aos desafios reais do cotidiano escolar nos dias atuais.

Mesmo em meio toda essa cogitação, acredita-se que a formação passou a ser interpretada como um processo contínuo e necessário ao profissional que precisa ter diferentes oportunidades para aperfeiçoar-se ao longo de sua carreira. O que não é mais admissível é acreditar, nos dias hodiernos, nas atividades tradicionais de um profissional sem nenhuma formação. Os profissionais precisam deixar a zona de conforto e partir em busca de inovações e melhores condições que lhes deem suporte para avaliar melhor o potencial dos antigos e novos saberes.

Essas análises, a respeito dos profissionais da educação têm deduzido, como um de seus pressupostos básicos, a certeza de que o professor é o mero sujeito do trabalho que realiza e longe de ser um repassador de conhecimentos produzidos por outros.

A formação inicial é estratégica, porque possibilita a constituição de um repertório de conhecimentos a serem ensinados e que embora sendo indispensável não seja suficiente. É preciso viabilizar a sua realização pelos docentes de forma autônoma, democrática e consciente para que os alunos possam aprender. Essa margem de saberes a serem conhecidos e mobilizados pelos docentes é uma gama de 
conhecimentos que devem ser articulados e contextualizados com reflexões sobre os diferentes significados e implicações da ação pedagógica.

\section{FORMAÇÃO DE PROFESSORES PARA OS ANOS INICIAIS DA EDUCAÇÃO BÁSICA - EAD}

Atualmente, o nosso país está formando mais professores para a educação infantil e séries iniciais do fundamental pelo Ensino à Distância - EAD, do que pelo sistema presencial. Resultados mostram que em 2009 65\% (sessenta e cinco por cento) dos estudantes graduaram-se por EAD, enquanto $45 \%$ (quarenta e cinco por cento) pela educação presencial. Resultado inédito que trouxe bons resultados, principalmente para aqueles que não se disponibilizavam de tempo para os estudos. (INEP - Instituto Nacional de Estatísticas e Pesquisas Anísio Teixeira)

Os níveis governamentais realizam suas verificações de maneiras bastante distintas. O PARFOR (Plano Nacional de Formação de Professores da Educação Básica) e a UAB (Universidade Aberta do Brasil) são de responsabilidade da CAPES (Coordenação de Aperfeiçoamento de Pessoal de Nível Superior) e os estudantes do setor privado bem como os egressos dos sistemas estaduais de Ensino Superior do INEP.

Por sua vez, educação à distância tem viabilizado a formação de muitos docentes, porém requer uma verificação nas suas medidas para adequá-las às necessidades dos alunos brasileiros, especialmente àqueles que tiveram uma formação deficitária na educação básica. Diante dessa preocupação, surgem os questionamentos: a educação à distância têm realmente garantido uma formação que atenda as expectativas dos nossos professores? Esses docentes estão preparados para trabalharem uma educação de qualidade?

Segundo a presidente da Comissão Bicameral do Conselho Nacional de Educação, Clélia Brandão, não há ferramentas específicas para mensurar, de forma segura, o desenvolvimento dos profissionais formados pelo EAD, ficando a cargo exclusivo dos pais de alunos, gestores públicos e da sociedade a tarefa avaliadora, uma vez que é 
desta colaboração que surgirão os melhores resultados. Nesse contexto, há ainda a ausência de uma supervisão atuante sobre a qualidade do ensino ofertado pelos nossos profissionais. E, por conseguinte, destaca-se também a carência de infraestrutura para que o EAD possa oferecer resultados satisfatórios. (Cleuza Repulho, presidente da UNDIME)

Em nosso país a Educação à Distância surge como mera necessidade, tendo em vista alguns empecilhos como: a dimensão continental do território brasileiro, a carência financeira de grande parte da população, principalmente as que habitam afastadas dos centros, pela dificuldade de deslocamento, alta carga horária de muitos professores que impossibilita a sua qualificação em cursos presenciais, entre outros.

\section{A FORMAÇÃO DE PROFESSORES PARA O ENSINO MÉDIO}

Durante décadas vêm-se debatendo sobre a formação de professores para o ensino médio no Brasil, o que não tem sido fácil devido alguns aspectos diferenciadores. Notadamente, há a falta de interesse de formação na área supostamente pelos baixos salários e pela inadequação de políticas educacionais que venham oferecer um bom andamento no setor. Por outro lado, a preparação de professores tem sido assunto de intensas e constantes discussões, tanto no Brasil quanto em âmbito internacional, envolvendo problemas não só pedagógicos, mas também ideológicos e filosóficos e à proporção em que se vai debatendo tais problemas, novos elementos surgem ao debate.

Diante da situação deficitária, na educação básica em nosso país, a atribuição pelas falhas e fracassos no sistema educacional recai, comumente, sobre os docentes e seus formadores. E por saber que no bojo do sistema educacional ainda existe as práticas pedagógicas tradicionais embasadas na convicção de que o certo é oferecer conteúdos, na maioria das vezes, irrelevantes, surge à necessidade de uma discussão da possibilidade de ensinar exclusivamente aos futuros professores, os conteúdos curriculares específicos que devem ser repassados aos seus alunos, tanto no ensino fundamental, quanto no médio, focalizando o que realmente é do seu interesse e que obviamente, esteja nos planos práticos da vida cotidiana. 
$\mathrm{Na}$ verdade, o que se necessita é da preparação de docentes em cursos de licenciaturas que possam firmar pactos com os centros de ensino, onde os discentes sejam o centro das decisões. É necessário que docentes e discentes adquiram a capacidade de produzir, construir e criticar, usando adequadamente, concepções próprias, desprendendo assim, das informações secundárias, e talvez desnecessárias, que lhes foram oferecidas como conteúdos complementares.

A praticidade é componente essencial e imprescindível na missão do professor, cabendo-Ihe o dever de lidar com equipamentos tecnológicos que venham dar-lhe suporte pedagógico, mas também ser hábil na improvisação quando a instituição não dispuser dessas ferramentas. Qualquer mudança que facilite e produza um ensino significativo faz parte da estratégia profissional.

(Educ. Soc. Campinas, vol. 25, n. 89) No entanto, deve-se levar em consideração que existem propostas substanciais para as políticas conservadoras que mesmo sofrendo críticas, podem oferecer algumas contribuições para o aprimoramento da formação docente, mesmo com a impossibilidade de resolver uma diversidade problemática na área. Contudo, vale apena salientar que não existe uma proposta salvadora que venha resolver os constantes problemas enfrentados no terreno da formação docente. $O$ trabalho no campo pedagógico só decolará se as tentativas de melhoria se abrir às críticas rumo a superação dos entraves que, obviamente, dificultam o desenvolvimento. Considera-se um grave problema no campo educacional a crença de que há probabilidade de se encontrar uma solução final para certos problemas. Segundo (Tardif), à medida que um saber vai se desenvolvendo e sistematizando, mais se revela intenso e complexo o processo da aprendizagem que se busca.

Para (Elliot, 2001) as críticas intituladas "ineficientes" nos sistemas burocráticos do governo, oferecem lacunas à abertura e legitimidade à infiltração crescente de uma lógica administrativa do setor privado. Essa lógica vai, paulatinamente, introduzindo formas, bastantes sutis, porém o seu principal objetivo, é analisar o desempenho de profissionais e instituições. Baseando-se em (Lyotard), o autor garante que em uma cultura de desempenho, a "qualidade" é resultado financeiro, incorporando três características operacionais: economia, eficiência e efetividade. 
(Ball, 2003, p. 218) emenda que na cultura do desempenho, o que se tem explicitado à comunidade educacional e ao público, é os equívocos cometidos, o que deixou de ser feito, sem uma análise ou justificativa das metas almejadas por essas instituições, e não pelos aspectos positivos das atividades pedagógicas. Portanto, o que não for mensurado e nitidamente observado, perde a sua legitimidade para esse tipo de avaliação. Vale apena salientar que nas concepções de (Ball, 2001 e Elliot, 2001), as instituições de ensino e os profissionais da educação imersos nessa cultura, vão eixando o interesse de trabalhar atividades e aspectos que não condigam com os indicadores de desempenho ou seja, os discentes concluem, logo nas séries iniciais do ensino fundamental, por terem sidos treinados à obtenção de bons resultados nas avaliações, em vez de serem educados no sentido amplo deste termo.

\section{DESESTÍMULO NA DOCÊNCIA}

A docência é uma área que, a modéstia parte, deveria ser a mais cobiçada dentre muitas, levando-se em conta a sua imprescindível atuação no galga mento em busca de outras. Jamais um profissional chegaria ao cume cobiçado, sem antes passar por um pedagogo. Contudo, há um acentuado desestímulo para a formação e a atuação de profissionais na área. Há pouco tempo, uma auditoria do TCU (Tribunal de Contas da União) em parcerias com os TCEs (Tribunais de Contas dos Estados), indicou a carência de pelo menos 32 mil professores com formação específica nas doze disciplinas obrigatórias da educação básica.

Um dos maiores entraves e geradores do problema são os salários baixos na docência que deixam de atrair jovens no ensino superior. Mesmo com a criação da Lei do Piso Salarial Nacional, (11.738/2008) que proíbe estados e municípios pagarem abaixo dele, com fixação de $R \$ 1.917,78$ (hum mil, novecentos e dezessete reais e setenta $e$ oito centavos), em 2015, com jornada de 40 horas semanais, para o magistério, ainda é considerado um valor aquém das expectativas para esses profissionais. Inclusive, os registros de evasão na educação básica para aqueles que optaram pela carreira docente, é cada vez maior, por lamentarem insatisfação no trabalho e desprestígio profissional. 
Diga-se de passagem, que há algumas décadas, o trabalho docente era mais bem reconhecido pelos alunos. Temiam, amavam, respeitavam e obedeciam aos seus professores. Espelhavam-se neles e até orgulhavam-se em comentar as aulas do dia. Realizavam, com prazer, as tarefas solicitadas e competiam as melhores notas. Em suas atividades lúdicas, incluíam sempre "brincar de professor". Chegavam a imitálos e tinham postura como tal. Não dispunham de transporte escolar, materiais pedagógicos sofisticados e nem tecnológicos. Realizavam pesquisa de campo, em vez de internet e, antes de entregar, faziam uma prévia leitura para certificarem-se do conteúdo. Os professores recebiam elogios, respeitosos abraços e às vezes presentinhos.

E nos dias hodiernos? Perceptivelmente está tudo diferente. $\mathrm{O}$ aluno passou a, ser o verdadeiro protagonista na história educacional. Graças a superproteção e a isenção de punição disciplinar, surgem, como consequências, o desrespeito e a desobediência. São comuns os xingamentos, os palavrões os ataques verbais e físicos, além de tentativas e assassinatos de professores.

Diante desse turbilhão de problemas, origina a desmotivação por uma das mais importantes profissões do mundo: a pedagogia. A área da docência fica, de certo modo, desprovida de atrativo, principalmente para aqueles que não conduzem nas próprias veias a paixão pela profissão e a honra de compartilhar com os seus saberes a construção dos pilares mais cobiçados, desde os tempos extemporâneos: a educação. Doar-se à docência é, ao mesmo tempo, contribuir para a queda das perversas estatistas que a sociedade vivencia.

Segundo Izabela S. Grispino, nos últimos anos, o número de candidatos ao ingresso do curso superior, na formação docente vem decrescendo acentuadamente. Em algumas regiões do Brasil já existe a escassez desses profissionais, com tendência de crescimento nos próximos anos. Não é demais acrescentar que esses resquícios são resultados da cruel desvalorização, descrédito e desprestígio desses profissionais. Muitos especialistas em educação acreditam que, se não houver menção a esta área, com o injeta mento de recursos para o reverti mento dessa imagem desfavorável a que hoje assistimos, em tempo breve, poderá tornar-se 
insustentável. Os desânimos docentes vieram à tona. Os baixos salários, as superlotações, os desrespeitos e as desvalorizações, deixam esses profissionais desestimulados e sem expectativas de melhoria na carreira.

Não é à toa que a autoestima dos docentes está em baixa, justamente por sentiremse desrespeitados pela sociedade por não conseguirem avançar e ofertar a qualidade tão necessária na atualidade. Esses profissionais gritam por suporte, conclamam melhores condições de trabalho e uma qualidade de vida decente, para, evidentemente, poder enfrentar ferrenhamente, os desafios da vida e consequentemente, oferecer resultados satisfatórios aos seus alunos e a sociedade como um todo. Se isso não se consumar, se os deveres políticos continuarem falhando, os jovens continuarão buscando outras profissões.

Segundo a UNESCO - 2003, os professores brasileiros do ensino médio cumprem até tripla jornada semanal, porém o salário médio está entre os mais baixos dos países desenvolvidos, ficando apenas acima do Peru e Indonésia.

Outra grave defasagem é que o nosso país possui a sexta maior média de aluno/professor, $(28,9)$ no ensino fundamental e $(38,6)$ no ensino médio, quando o máximo recomendado pela UNESCO e a OIT, é de 20 a 30 alunos por professor, ficando evidente que esse excessivo número de alunos nas classes traz, como consequências, o estresse ao professor e o baixo rendimento dos alunos.

De maneira que o desestímulo ao magistério têm suas razões por explicitar uma imagem de penúria, desrespeito e desconsideração aos profissionais que se doam em prol do desenvolvimento da sociedade.

Uma recente pesquisa internacional mostrou que, o Brasil fica em penúltimo lugar em relação ao respeito e à valorização dos profissionais em educação.

Com base no PNE (Plano Nacional de Educação), sancionado pela Lei 13.005 de 25 de junho de 2014, que prevê em uma de suas Metas, a formação e a valorização do professor, alimenta-se essa expectativa de que o estímulo à docência seja superado, 
que o professor volte e se orgulhar de sua árdua missão e possa continuar lapidando, com amor, as mente humanas.

\section{CONCLUSÃO}

Todavia, enfatiza-se a necessidade da busca urgente de mecanismos que possam discutir e viabilizar o cumprimento da LDB - Lei de Diretrizes e Bases da Educação Nacional e consequentemente soluções positivas no âmbito educacional. É preciso criar-se uma junção de forças de toda a sociedade para o resgate da credibilidade do sistema educacional no Brasil, consolidando a meritocracia dos nossos docentes, que não se cansam, jamais, de lutar crucialmente pelas mudanças sociais positivas ao longo dos tempos.

Há, ainda, uma necessidade muito grande de correção no sistema educacional brasileiro, no que diz respeito à fomentação numerológica e resultados meramente estatísticos. A qualidade de ensino em nosso país está bastante aquém das expectativas e não dá mais para esperar algo que não chega nunca. O presidente dos Estados Unidos, Barack Obama presume: "A mudança não virá se esperarmos por outra pessoa ou outros tempos. Nós somos aqueles por quem estávamos esperando. Nós somos a mudança que procuramos."

Está na hora de uma revolução educacional. Chega de tecer reclames e colocar a culpa sabe-se lá em quem. A culpa é de toda a sociedade que não leva a sério o assunto educação, mesmo sabendo que os países mais ricos do mundo são aqueles que apostaram e investiram, sem poupar na sua área. Se cada um fizesse a sua parte, cumprisse com a sua responsabilidade e desempenhasse o papel que the fora confiado, certamente, a imagem da educação brasileira não precisaria de maquiagens milagrosas e o seu histórico apresentado não sofreria restrições.

É absolutamente correto afirmar que na formação docente estão inseridas disciplinas que possibilitam uma profunda reflexão sobre os mais diferentes significados e implicações da ação pedagógica, tanto na dimensão social, política e cultural da educação escolar, de forma que o professor transforme-a em um proveitoso diálogo 
com seus alunos, no intuito de alcançar o que, obviamente, planejou. Os corpos docentes são profissionais que foram convidados a cumprirem com uma das mais árduas missões, definindo suas práticas em relação aos saberes que possuem e multiplicando-os através de suas aulas. Por isso, o professor é, antes de tudo, um ser que sabe compartilhar, humildemente, os seus saberes.

\section{REFERÊNCIAS}

MYRIAN, Krasilchik M. Docência no Ensino Superior;

TRANTMAM, N. Learning to teach;

WEAWER, Higtower, Marcus An Ecology;

LDB - Lei de Diretrizes e Bases da Educação Brasileira;

PNE - Plano Nacional de Educação;

BAAL, 2003, pag. 218 e ALLIOT, 2001;

MORETTI, Isabella. Regras da ABNT;

MONTEIRO, Ana Maria. Profạ. De Didática de História na UFRJ, Mestre em História na UFF e Doutoranda em Educação pela PUC/Rio;

CADERNOS DE EDUCAÇÃO, Diretrizes para a Carreira e Remuneração; 